\title{
Acquired laryngeal stenosis in infants and children treated by laryngofissure and stenting
}

\author{
L.J. Hoeve*, R.N.P. Berkovits, O. Eskici, C.D.A. Verwoerd \\ Department of Otorhinolaryngology, Sophia Children's Hospital/Erasmus University Rotterdam, \\ Rotterdam, The Netherlands
}

Received 19 July 1995; revised 14 November 1995; accepted 18 November 1995

\begin{abstract}
Thirty young patients with acquired laryngeal stenosis were treated by means of a laryngofissure and stenting. The age distribution suggested two subgroups: infants aged $0-2$ years $(n=24)$, and children aged 6-16 years $(n=6)$. The causes of the stenosis and the treatment results were different in these subgroups. Treatment resulted in successful decannulation in 22 of 24 infants, and in 5 of 6 children. Treatment included a re-operation in two patients. In 1 patient the therapy failed, and 2 patients died after fatal complications. Decannulation rate, duration of the tracheotomy, and the number of re-operations compare favorably to the results of other centers. The longer duration of stenting, and the high mortality rate may be considered disadvantages.
\end{abstract}

Keywords: Acquired laryngeal stenosis; Laryngofissure; Larynx stent; Infants; Children

\section{Introduction}

Acquired laryngeal stenosis in children is usually caused by prolonged intubation, and seldom by acute endolaryngeal injury. Its treatment has varied from a tracheotomy and wait-and-see in the past, to extensive surgery in combination with endoscopic procedures nowadays [7-10,12,15-17,19,20,25,29-31,34,38,40-43,46]. After surgery the laryngeal lumen is usually 'stented' for some weeks or even months $[1,10,17,23,27,32,33,39,44,45]$.

\footnotetext{
* Corresponding author.
} 
Three types of current surgical treatment may be distinguished: laryngofissure, laryngofissure and interpositioning of a graft and resection of the stenotic area.

The laryngofissure is based on the concept of augmenting the laryngeal lumen by widening of the cartilaginous framework rather than by excision of scar tissue, as introduced by Réthi, and later supported by Grahne, Evans, Cotton and Fearon $[10,17,19,24,38]$.

An anterior incision of a child's cricoid cartilage results in a gap of a few millimeters [12], which could be explained by the release of interlocked stresses in the cartilaginous ring $[2,4]$. Additional division of the posterior cricoid lamina creates posteriorly a 'hinge-joint' which permits the cricoid halves to rotate outwardly by the contractional force of the cricopharyngeus muscle [4]. This outward rotation could be counteracted by scar tissue formation in the anterior gap. Retraction of scar tissue can be prevented by long-term stenting or by interpositioning of a graft.

A recent development is resection of the stenotic area including a part of the deformed cricoid and primary anastomosis of the larynx and trachea [31].

The results of the different treatment modalities are usually compared on the basis of decannulation rates. Other aspects, however, play an important role in the outcome as well: selection of patients, duration of treatment and complication rate.

The present study aims to describe the experience with laryngofissure in the Sophia Children's Hospital (Erasmus University Rotterdam) and compare the results with those in other centers.

\section{Methods: diagnosis and treatment}

Both flexible and open rigid laryngoscopy under general anesthesia were part of the pre-operative evaluation procedure. Patients with immobility of the laryngeal entrance, or with severe tracheomalacia, were not included in this series. Open rigid (video) laryngoscopy was performed to record the exact site and length of the stenosis. The consistency and the diameter of the stenosis were examined with Hegar dilators. The measured diameter was compared with the expected diameter, taken from a table with age-dependent endotracheal tube sizes [6]. Subsequently the stenosis was classified according to Cotton (grade 1-4) (Table 1) [10].

Pre-operative evaluation also included esophageal $\mathrm{pH}$ measurement. If gastroesophageal reflux was noted, treatment was started well before the stenosis treatment.

Table 1

Cotton classification of stenosis [10]

Grade $1=<70 \%$ Obstruction

Grade $2=70-90 \%$ Obstruction

Grade $3=>90 \%$ Obstruction or obliteration, not including the glottis

Grade $4=$ Obliteration including the glottis 
Because all patients required intubation or a tracheotomy, pre-operative pulmonary function tests and speech tests were usually not possible.

A laryngofissure was not performed until the infant had reached a weight of $7 \mathrm{~kg}$. Two types of operations, both without interpositioning a graft, were performed:(1) anterior laryngofissure: a midline incision, or a castellated incision as described by Evans, through thyroid, cricoid and tracheal rings without division of the posterior cricoid lamina [17];(2) anterior and posterior laryngofissure: an anterior incision of the thyroid cartilage, the cricoid and the proximal tracheal rings, and posteriorly a midline incision of the posterior cricoid lamina [38]. Post-operatively all patients were allowed to wake up and breathe spontaneously.

Post-operatively the laryngeal lumen was splinted by either a siliconized silicone rubber stent or a nasotracheal tube of the same material. The stents and tubes were designed by one of the authors (RNPB) [5]. The cylindrical stent is available in all desired lengths and diameters. The caudal end is sutured to a metal tracheotomy tube with an inner cannula. By means of a suture through pharynx and nose the cranial end of the stent is anchored to a small ring (from a jeweler) pierced through an earlobe.

The stent or tube had to be replaced by a new one every 3-4 weeks because it became colonized by micro-organisms. Granulations were then removed or injected with corticosteroids. Usually this procedure lasted approximately $10 \mathrm{~min}$ under general anesthesia. Most patients were discharged a few weeks after the laryngofissure, and were nursed by the parents. The stenting was discontinued as soon as granulations had disappeared, and the mucosa had healed. Subsequently the patient was decannulated after a few months of observation. Laryngobronchoscopy, pulmonary function tests and speech tests were not routinely performed during the follow-up period.

\section{Results}

\subsection{Pre-operative evaluation}

The reported series consists of a consecutive group of 30 young patients ( 19 boys and 11 girls) presenting with an acquired laryngeal or proximal tracheal stenosis between 1976 and 1993. Two subgroups can be distinguished: 24 infants (14 boys, 10 girls), most of whom were operated on in their second year of life, and 6 children ( 5 boys, 1 girl) operated on between 6 and 16 years of age (Table 2).

In the 'subgroup infants' the causes of the stenoses were: prolonged intubation in relation to prematurity (9 cases), traumatic intubation (5), repeated episodes of subglottic laryngitis (5), prolonged intubation in relation to surgery (4) and endolaryngeal tumor (1). The stenoses had been present between 3 months and 2 years at the time of the operation. Three infants had subglottic granulations completely obstructing the lumen, nine had grade 2 stenoses, eleven grade 3 and one grade 4 (Fig. 1). The indication for surgical treatment was a persistent need of a tracheotomy ( 22 cases), or repeated unsuccessful attempts to extubate the patients in spite of conservative treatment ( 2 cases). 
Table 2

Laryngofissure patients in Rotterdam, Sophia Children's Hospital

\begin{tabular}{|c|c|c|c|c|}
\hline Patients & LBS & Therapy & Result & FU \\
\hline \multicolumn{5}{|c|}{ Subgroup infants } \\
\hline $1 \mathrm{f} 3 \mathrm{y} 9 \mathrm{~m}$ & $0000 \mathrm{~g}$ & AP-S 99 & + & oy $9 \mathrm{~m}$ \\
\hline 2 f $2 y 5 m$ & $0 \bullet \bullet-\mathbf{g}$ & AP-S 18 & $\mathrm{D}$ & - \\
\hline $3 \mathrm{~m} 1$ y $2 \mathrm{~m}$ & $0 \bullet 0-\mathrm{g}$ & AP-S 84 & + & $0 \mathrm{y} 9 \mathrm{~m}$ \\
\hline $4 \mathrm{~m} \mathrm{ly} 1 \mathrm{~m}$ & $0002 \mathrm{~s}$ & AP-S 92 & + & $0 \mathrm{y} 4 \mathrm{~m}$ \\
\hline $5 \mathrm{~m} \mathrm{ly} 5 \mathrm{~m}$ & $0002 \mathrm{sc}$ & AP-S 82 & + & $7 y 8 \mathrm{~m}$ \\
\hline $6 \mathrm{~m} \mathrm{ly} 4 \mathrm{~m}$ & $0002 \mathrm{sc}$ & AP-S 204 & + & $2 \mathrm{y} 0 \mathrm{~m}$ \\
\hline 7 f 1 y $2 m$ & $0002 \mathrm{sc}$ & AP-S 87 & + & $0 \mathrm{y} 5 \mathrm{~m}$ \\
\hline $8 \int 1 \mathrm{y} 1 \mathrm{~m}$ & $00 \bullet 02 \mathrm{t}$ & A-S 49 & + & $5 y 9 \mathrm{~m}$ \\
\hline 9 f $0 y 5 m$ & $0 \bullet \bullet 2 s$ & AP-S 35 & + & $5 y 9 \mathrm{~m}$ \\
\hline $10 \mathrm{~m} 0 \mathrm{y} 10 \mathrm{~m}$ & $0 \bullet \bullet 2 s$ & A-S 153 & + & $0 \mathrm{y} 1 \mathrm{~m}$ \\
\hline $11 \mathrm{~m} \mathrm{ly} 8 \mathrm{~m}$ & $00 \bullet 2 s$ & AP-S 170 & + & $2 \mathrm{y} 2 \mathrm{~m}$ \\
\hline $12 \mathrm{f} 1 \mathrm{y} 4 \mathrm{~m}$ & $00 \bullet 2 \mathrm{sc}$ & A-S 61 & $\mathrm{D}$ & - \\
\hline $13 \mathrm{~m} \mathrm{ly} 9 \mathrm{~m}$ & $0003 \mathrm{~s}$ & AP-S 273 & + & $6 y 5 \mathrm{~m}$ \\
\hline $14 \mathrm{~m} 1 \mathrm{y} 1 \mathrm{~m}$ & $0003 \mathrm{~s}$ & AP-S 125 & + & $0 \mathrm{y} 6 \mathrm{~m}$ \\
\hline $15 \mathrm{~m} 2 \mathrm{y} 3 \mathrm{~m}$ & $0003 \mathrm{~s}$ & AP-S 43 & + & $1 \mathrm{y} 6 \mathrm{~m}$ \\
\hline $16 \mathrm{f} 1 \mathrm{y} \mathrm{lm}$ & $00 \bullet 3 \mathrm{~s}$ & AP-S 113 & + & 1y $2 \mathrm{~m}$ \\
\hline $17 \mathrm{~m} 1 \mathrm{y} 1 \mathrm{~m}$ & $0003 \mathrm{~s}$ & AP-S 183 & + & $0 \mathrm{y} 10 \mathrm{~m}$ \\
\hline $18 \mathrm{f} 0 \mathrm{y} 10 \mathrm{~m}$ & $00003 \mathrm{~s}$ & AP-S 140 & - & Reop. + \\
\hline $19 \mathrm{~m} \mathrm{ly} 0 \mathrm{~m}$ & $0003 \mathrm{~s}$ & AP-S 42 & + & $0 \mathrm{y} 4 \mathrm{~m}$ \\
\hline $20 \mathrm{f} 1 \mathrm{y} 6 \mathrm{~m}$ & $0003 \mathrm{sc}$ & A-I 102 & + & $13 \mathrm{y} 6 \mathrm{~m}$ \\
\hline $21 \mathrm{f} 0 \mathrm{y} 9 \mathrm{~m}$ & $0 \bullet 03 \mathrm{~s}$ & AP-S 113 & + & $0 \mathrm{y} 4 \mathrm{~m}$ \\
\hline $22 \mathrm{~m} \mathrm{0y} 6 \mathrm{~m}$ & $0 \bullet 03 \mathrm{sc}$ & A-I 66 & + & $9 y 5 \mathrm{~m}$ \\
\hline $23 \mathrm{~m} 1 \mathrm{y} 1 \mathrm{~m}$ & 0000 3s & AP-S 285 & + & $2 y 7 \mathrm{~m}$ \\
\hline $24 \mathrm{~m} \mathrm{lym}$ & $0 \bullet \bullet-4 s$ & A-S 107 & + & $0 \mathrm{y} 3 \mathrm{~m}$ \\
\hline \multicolumn{5}{|c|}{ Subgroup children } \\
\hline $25 \mathrm{~m} 6 y 10 \mathrm{~m}$ & $0003 \mathrm{~s}$ & Ac-I 48 & + & $11 \mathrm{y} 0 \mathrm{~m}$ \\
\hline $26 \mathrm{~m} 15 \mathrm{y} 4 \mathrm{~m}$ & $00003 \mathrm{~s}$ & A-S 181 & + & $1 \mathrm{y} 9 \mathrm{~m}$ \\
\hline $27 \mathrm{~m} \mathrm{9y} 4 \mathrm{~m}$ & $0 \bullet 03 \mathrm{~s}$ & AP-S 90 & + & $2 \mathrm{y} 0 \mathrm{~m}$ \\
\hline $28 \mathrm{f} 6 \mathrm{y} 1 \mathrm{~m}$ & 0000 3st & AP-S 189 & + & $4 y 5 \mathrm{~m}$ \\
\hline $29 \mathrm{~m} 8 \mathrm{y} 3 \mathrm{~m}$ & $0 \bullet 04 s$ & AP-S 350 & - & Lost \\
\hline $30 \mathrm{~m} 12 \mathrm{y} 0 \mathrm{~m}$ & $0 \bullet \bullet 4 s$ & AP-S 230 & - & Reop. + \\
\hline
\end{tabular}

Serial number of patient, sex, and age at operation; localization, grade and consistency of the stenosis; type of operation, stent or intubation and duration (days); result of the treatment; follow up.

Laryngobronchoscopy (LBS): $0000 / \bullet \bullet \bullet$, Supraglottis/glottis/subglottis/proximal trachea; $(O$, no stenosis; •, stenosis);1,2,3,4, stenosis grade (Cotton) [10]; g, granulation tissue; s, scar tissue; c, cartilaginous stenosis; $t$, tumor.

Therapy: A, Anterior incision; Ac, anterior castellated incision; P, posterior cricoid incision; S, laryngeal stent; I, nasotracheal intubation.

Result: + , Decannulation or extubation; -, no decannulation or extubation; D, died.

Follow-up (FU): Reop. +, successfully reoperated; Lost, lost from follow-up.

In the 'subgroup children' the causes were: prolonged intubation after a traffic accident (2), prolonged intubation in relation to surgery (2), prolonged intubation for M. Guillain Barré (1) and endolaryngeal tumor (1). These patients were operated on between 4 months and 10 years after the endolaryngeal injury. Four 
grade 3 and two grade 4 stenoses were observed (Fig. 1). Four children had a tracheotomy, two had been treated previously with intubation, but without success.

More data concerning the individual patients, and the observed stenosis, are listed in Table 2 . No patients died in the period between presentation and surgery.

\subsection{Surgical treatment and results}

In the 'subgroup infants' the mean age at the time of surgery was 17 months $(5-45 \mathrm{~m})$. Six anterior laryngofissures, and 18 anterior and posterior laryngofissures were performed. Twenty-two infants were stented, two intubated after surgery. Stenting lasted a mean 123 days (35-285), intubation 66 and 102 days, respectively, and decannulation took place a mean 187 days (43-449) after the operation in the successfully treated patients. In most infants the number of procedures under general anesthesia (laryngofissure, stent replacement and laryngoscopies) was between 6 and 10 .

Twenty-one of 24 infants could be decannulated or extubated after one operation. In one case (18) the therapy failed. This infant was later re-operated (laryngofissure with interpositioning of a costal cartilage graft), and subsequently decannulated. Two patients died during the treatment (Table 2).

\section{Number of patients and grade of stenosis according to age at operation.}

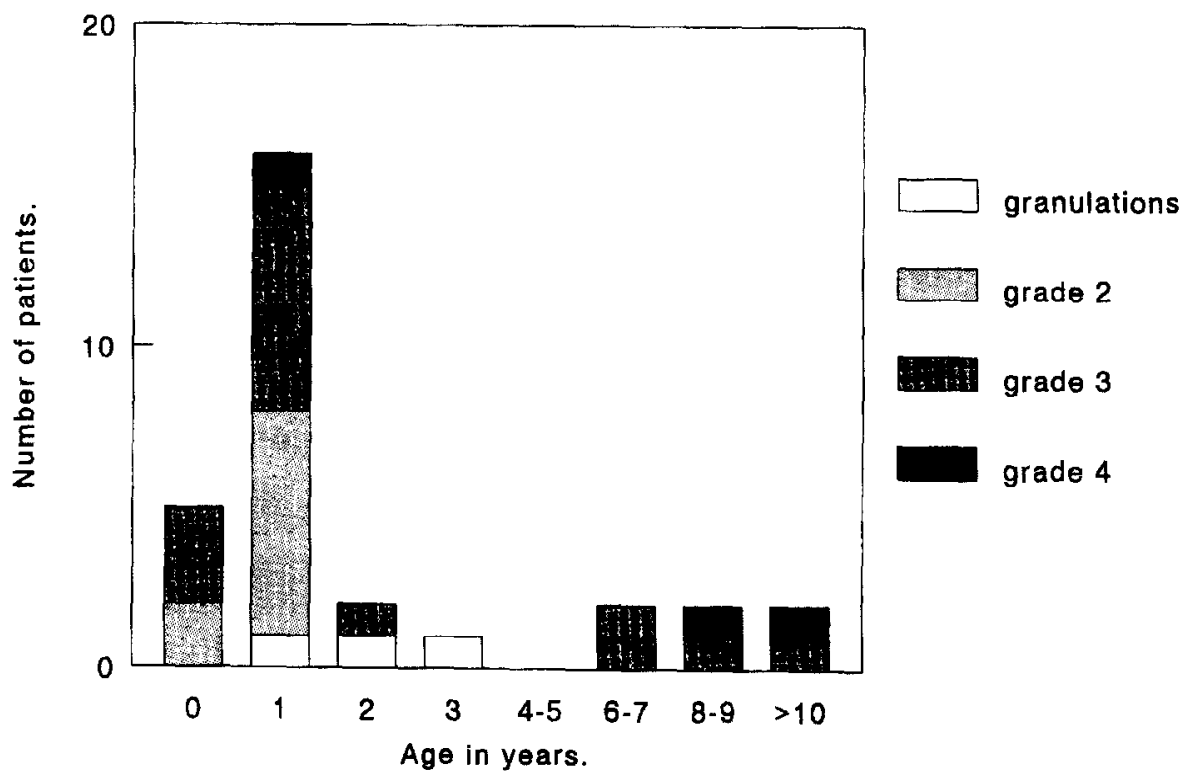

Fig. 1. Number of patients and grade of stenosis per age group. 
The mean follow-up period after decannulation of the 21 cured infants was 2 years and 11 months. One infant (9) initially had signs of hoarseness and aspiration of food, and later she had slight complaints of inspiratory stridor on exertion, which did not warrant laryngoscopy. The tracheotomy openings spontaneously closed after decannulation in most infants. In five cases a tracheocutaneous fistula had to be closed surgically.

In the 'subgroup children' one child underwent an anterior laryngofissure, another an anterior laryngofissure with a castellated incision, and four a combined anterior and posterior laryngofissure. One child was intubated, five children were stented after surgery. The intubation lasted 48 days, and the stenting 90,181 and 189 days, respectively, in the 4 successfully treated patients. The extubation or decannulation took place 48, 97, 258 and 343 days, respectively, after the operation. Between 3 and 12 procedures in general anesthesia were needed.

Four children could be decannulated or extubated. In the other two $(29,30)$ the therapy failed; they both had a grade 4 glottic and subglottic stenosis. The stent was removed after 350 and 230 days, respectively, when the airway was completely covered with epithelium without any granulations. One of these children (29) is lost from follow-up, the other (30) has been re-operated (laryngofissure with interpositioning of a costal cartilage graft), and has been decannulated (Table 2).

The 4 successfully treated children were followed between almost 2 and 11 years. One child (28) had dysphonia probably as a result from scarring of the vocal cords, and a slight, permanent inspiratory stridor. A second child (26) had inspiratory stridor on exertion. The severity of the complaints did not warrant laryngoscopy.

The final decannulation rate of all patients (infants and children) was $90 \%$, the decannulation rate after the first operation was $83 \%$.

\subsection{Complications}

The complications, summarized in Table 3, are either related to surgery or to the post-operative period. They range from frequently-occurring, relatively minor events, such as respiratory tract infections, to life-threatening events, such as accidental extubation or tube obstruction.

In the 'subgroup infants' complications occurred in 20 of the 24 patients (Table 3). Laryngeal or tracheal granulations were observed in 13 infants. These gradually disappearing granulations were the main factor responsible for prolongation of the stenting. More than half of the infants had at least one episode of respiratory tract infection, which always responded to antibiotics. Dysphagia and aspiration, probably caused by the presence of the stent and the cannula, necessitated nasogastric tube feeding in eight infants. These symptoms, which were only observed in the infants, and not in the older children, disappeared only gradually after decannulation. Other complications were obstruction of the endotracheal or tracheotomy tube, accidental extubation or decannulation, and stent disconnection from the tracheotomy cannula. These potentially life-threatening events, only observed in four infants, could be adequately managed without cerebral or other damage. Two infants discharged to other institutions, both with a stent in place, died of cardiac 
Table 3

Laryngofissure patients in Rotterdam, Sophia Children's Hospital, complications in the subgroups infants and children

\begin{tabular}{llll}
\hline & Infants & Children & Total \\
\hline Surgery related: & & & \\
Wound infection & 1 & 0 & 1 \\
Subcutaneous emphysema & 0 & 1 & 1 \\
Pneumothorax & 1 & 0 & 1 \\
& & & \\
Related to the post-operative period: & 13 & 4 & 17 \\
Granulations in larynx or trachea & 13 & 4 & 8 \\
Respiratory tract infection & 8 & 0 & 4 \\
Dysphagia, aspiration & 4 & 0 & 2 \\
Obstruction of tube & 2 & 0 & 2 \\
Accidental decannulation or extubation & 2 & 0 & 4 \\
Fatal cardiac arrest & 1 & 0 & 17 \\
Stent disconnection & 4 & 0 & \\
No complications & & & \\
\hline
\end{tabular}

The total numbers of patients in which the various complications occurred are given.

arrest. One (12) had cardiac and other congenital anomalies, the other (2) was healthy except for the laryngeal stenosis. It was reported that neither inspection of the tracheotomy tube and the stent, nor autopsy revealed the cause of these fatal events.

In the 'subgroup children' no life-threatening events were recorded. Frequent complications were again granulations and respiratory tract infections.

\section{Discussion}

The causes of the stenoses in the reported group of patients are heterogenous: prolonged intubation, endolaryngeal tumor and recurrent subglottic laryngitis. All patients however suffered from serious lesions leading to endolaryngeal scar tissue formation. Also, the treatment methods are variable: during the first years of the studied period usually only anterior cricoid splits were done, including one castellated incision, while later anterior and posterior incisions were combined. In the early years a few patients were post-operatively intubated, later the large majority was stented. These variations in cause and treatment limit the possibilities to compare treatment results in the various centers.

Our patients could be divided into two subgroups (infants and children) that differed in number, in sex ratio, in cause and severity of the stenosis, and in treatment results, including complications.

Most of the patients were infants, which may be explained by two reasons. Firstly, it is particularly pre-term infants, who are treated with prolonged intubation and ventilation, a treatment which may cause laryngeal stenosis [18]. Secondly, 
in young infants the subglottic diameter is proportionally small, and increases rapidly. Selecting the correct size of the endotracheal tube is therefore a critical procedure with the risk of intubation with too large a tube.

The majority of the patients were boys, and in the subgroup children male predominance was even more pronounced than in the infants. In both subgroups most stenoses occurred after prolonged intubation. In the infants the necessity of intubation was often related to prematurity.

Similar differences in age, number of patients per age group, and cause of the stenosis are found in the London series [35,36]. The patients in Cincinnati are more evenly distributed over the age groups [11]. Differences in grade of stenosis per age group are not reported by other centers, but may be an important factor in the outcome of treatment.

The complications in the subgroup infants appeared to be more serious and more frequent than those in the subgroup children. Life-threatening complications occurred only in infants. Two infants died under unclear circumstances after discharge to other hospitals, both had a stent connected to a tracheotomy cannula. In this respect it may be mentioned that the mortality rate of a tracheotomy in infants is reported to be $0-5 \%$ [22]. Complications, including mortality, are related to younger age and longer duration of the tracheotomy [14,21,22]. The risks are probably further increased if a stent is connected to the cannula. The period of tracheotomy and stenting should therefore be as short as possible. Operation at a young age and early decannulation should be aimed for. Serious dysphagia and aspiration, continuing for months after decannulation, occurred only in infants. This problem is probably related to long-term nasogastric tube feeding resulting in inefficient reflexes, and requires an intensive therapeutic training program.

The treatment results in the infants were better than those in the children of the reported series, both in terms of decannulation rate and of complaints after decannulation. The stenoses, however, were more serious in children than in infants (Fig. 1). Other centers report a relation between grade of stenosis and treatment result $[10,31,35]$, but do not report a relation between age and treatment result, or between age and grade of stenosis [10,26,28,31,35].

The decannulation rate of 30 laryngofissures without graft in Rotterdam is $83 \%$. Cotton (Cincinnati) reports a $66 \%$ decannulation rate after 73 laryngofissures without a graft [10]. The stenoses in the Cincinnati group of patients, however, were more serious than those in Rotterdam: 11 grade 4 stenoses of 73 in Cincinnati, versus 3 of 30 in Rotterdam [10]. Another sizeable group of laryngofissures without graft is reported from London [3]. Unfortunately, separate decannulation rates of the operations with and without graft are not presented; the first operation decannulation rate is $63 \%$.

The decannulation rate of operations with a graft in Cincinnati is $78 \%$, the severity of the stenoses in that group of patients is comparable with that of the Rotterdam patients: 17 grade 4 stenoses of 174, versus 3 of 30 in Rotterdam [10].

The partial cricoid resection and laryngotracheal anastomosis in Lausanne has a very high decannulation rate $(93 \%)$ [31]. Though the number of patients is not large, and the indications are limited to subglottic and tracheal stenoses, the results 
are promising, especially in patients with a reported grade 4 stenosis. However, a grade 4 stenosis in the current Cotton classification implies obliteration and no vocal cords identifiable [10]. As such a high stenosis cannot be cured by cricoid resection, it seems likely that the old Cotton classification was used in Lausanne, and that the reported grade 4 stenoses are in fact grade 3 (subglottic obliterations) [11].

A recent development is the single stage laryngotracheoplasty, a laryngofissure with interpositioning of a cartilage graft anteriorly and/or posteriorly, followed by a few weeks of intubation $[29,40]$. As this treatment method is suitable for young infants, the tracheotomy period is considerably shortened. The treatment results in grade 2 and 3 stenoses are very good, a decannulation rate of more than $90 \%$ is reached. The method is not advised for patients with a grade 4 stenosis $[29,40]$. Other methods are reported to have similarly good results in grade 2 and 3 stenoses. $[3,10,35,36]$

The number of major operations per patient in Rotterdam is low compared to other centers, the number of minor procedures (endoscopies, replacement of stents) are not reported by other centers. [3,10,26,29,35,36,40,46]

Other important factors for assessing the long-term results are: growth of the larynx, especially the subglottic diameter; voice; respiratory function; growth of the patient.

These factors have not yet been subject of systematic research [13], but could add to an adequate evaluation of treatment strategies.

\section{Conclusions}

The method used in Rotterdam, laryngofissure without graft, compares favorably with methods used in other centers in terms of decannulation rate, and number of major operations. The longer duration of tracheotomy and stenting, and the repeated endoscopic procedures are disadvantages. The presence of a stent in the larynx may contribute to dysfunction and damage to the glottis, formation of granulation tissue and increased tracheotomy risks. Treatment methods with a reduced stenting period such as single stage laryngotracheoplasty and partial cricoid resection are promising in that respect. A cartilage graft, though gradually replaced by fibrous tissue [37], prevents retraction of scar tissue. Moreover, the perichondrium could provide a surface that is easily overgrown by regenerating mucosa, and therefore gives rise to less granulation formation than an anterior gap not closed by a graft.

Comparison of the results of various operation techniques, however, does not lead to unambiguous conclusions in this respect.

\section{References}

[1] Aboulker, P., Sterkers, J.M. and Demaldent, J.E. (1966) Modifications apportées à l'intervention de Réthi, interest dans les stenoses laryngo-tracheales et tracheales. Ann. Otolar. Chir. Cervicofac. 
$83,98-106$.

[2] Adriaansen, F.C.P.M., Verwoerd-Verhoef, H.L., Van der Heul, R.O. and Verwoerd, C.D.A. (1988) A morphometric study of the growth of the subglottis after interruption of the circular structure of the cricoid. Otorhinolaryngology 50(1), 54-66.

[3] Bailey, C.M. (1988) Surgical management of acquired subglottic stenosis. J. Laryngol. Otol. Suppl. 17, 45-48.

[4] Bean, J.K., Verwoerd-Verhoef, H.L. and Verwoerd, C.D.A. (1994) Intrinsic and extrinsic factors relevant to the morphology of the growing cricoid ring after a combined anterior and posterior cricoid split: an experimental study in rabbits. Int. J. Pediatr. Otorhinolaryngol. 29, $129-137$.

[5] Berkovits, R.N.P., Bos, C.E., Pauw, K.II. and De Gee, A.W.J. (1978) Congenital cricoid stenosis: pathogenesis, diagnosis and method of treatment. J. Laryngol. Otol. 92, 1083-1100.

[6] Bos, C.E., Berkovits, R.N.P. and Struben, W.H. (1973) Wider application of prolonged nasotracheal intubation. J. Laryngol. Otol. 87, 263-289.

[7] Cobb, W.B. and Sudderth, J.F. (1972) Intralesional steroids in laryngeal stenosis. Arch. Otolaryngol. 96, 52-56.

[8] Cotton, R.T. (1990) Management and prevention of subglottic stenosis in infants and children. In: Bluestone, C.D., Stool, S.E. and Scheetz, M.D. (Eds.), Pediatric Otolaryngology, 2nd edn. W.B. Saunders Company, Philadelphia, pp. 1194-1204.

[9] Cotton, R.T., Mortelliti, A.T. and Myer, C.M. (1992) Four-quadrant cricoid cartilage division in laryngotracheal reconstruction. Arch. Otolaryngol. Head Neck Surg. 118, 1023-1027.

[10] Cotton, R.T., Gray, S.D. and Miller, R.P. (1989) Update of the Cincinnati experience in pediatric laryngotracheal reconstruction. Laryngoscope 99, 1111-1116.

[11] Colton, R.T. (1984) Pediatric laryngotracheal stenosis. J. Pediatr. Surg. 19, 699-704.

[12] Cotton, R.T. and Seid, A.B. (1980) Management of the extubation problem in the premature child: anterior cricoid split as an alternative to tracheotomy. Ann. Otol. 89, 508-511.

[13] Cotton, R.T. (1991) The problem of pediatric laryngotracheal stenosis: a clinical and experimental study on the efficacy of autogenous cartilaginous grafts placed between the vertically divided halves of the posterior lamina of the cricoid cartilage. Laryngoscope 101 Suppl. 56, $1-34$.

[14] Crysdale, W.S., Feldman, R.I. and Naito, K. (1988) Tracheotomies: a 10-year experience in 319 children. Ann. Otol. Rhinol. Laryngol. 97, 439-443.

[15] Dedo, H.H. (1979) Endoscopic Teflon keel for anterior glottic web. Ann. Otol. Rhinol. Laryngol. $88,467-473$.

[16] Dedo, H.H. and Sooy, C.D. (1984) Endoscopic laser repair of posterior glottic subglottic and tracheal stenosis by division or micro-trapdoor flap. Laryngoscope 94, 445-450.

[17] Evans, J.N.G. and Todd, G.B. (1974) Laryngo-tracheoplasty. J. Laryngol. Otol. 88, 589-597.

[18] Fan, L.L., Flynn, J.W. and Pathak, D.R. (1983) Risk factors predicting laryngeal injury in intubated neonates. Crit. Care Med. 11, 431-433.

[19] Fearon, B. and Cotton, R. (1974) Surgical correction of subglottic stenosis of the larynx in infants and children. Ann. Otol. 83, 428 - 431.

[20] Fearon, B. and Cinnamond, M. (1976) Surgical correction of subglottic stenosis of the larynx. Clinical results of the Fearon Cotton operation. J. Otolaryngol. 56, 475-478.

[21] Gaudet, P.T., Peerless, A., Sasaki, C.T. and Kirchner, J.A. (1978) Pediatric tracheostomy and associated complications. Laryngoscope 88, 1633-1641.

[22] Gianoli, G.J., Miller, R.H. and Guarisco, J.L. (1990) Tracheotomy in the first year of life. Ann. Otol. Rhinol. Laryngol. 99, 896-901.

[23] Goode, R.L. and Shinn, J.B. (1977) Long-term stenting in the treatment of subglottic stenosis. Ann. Otol. 86, 795-798.

[24] Grahne, B. (1971) Operative treatment of severe chronic traumatic laryngeal stenosis in infants up to 3-years-old. Acta Otolaryngol. 72, 134-137.

[25] Hawkins, D.B. (1977) Glottic and subglottic stenosis from endotracheal intubation. Laryngoscope $87,339346$.

[26] Hof, E. (1987) Surgical correction of laryngotracheal stenoses in children. Prog. Pediatr. Surg. $21,29-35$. 
[27] Langman, A.W., Lee, K.C. and Dedo, H.H. (1989) The cndoscopic Teflon keel for posterior and total glottic stenosis. Laryngoscope 99, 571-577.

[28] Luft, J.D., Wetmore, R.F., Tom, L.W.C., Handler, S.D. and Potsic, W.P. (1989) Laryngotracheoplasty in the management of subglottic stenosis. Int. J. Pediatr. Otolaryngol. 17, 297-303.

[29] Lusk, R.P., Gray, S. and Muntz, H.R. (1991) Single-stage laryngotracheal reconstruction. Arch. Otolaryngol. Head Neck Surg. 117, 171-173.

[30] McIlwain, J.C. (1989) A historical overview of the aetiology and treatment of laryngeal stenosis. Arch. Otorhinolaryngol. 246, 336-340.

[31] Monnier, P., Savary, M. and Chapuis, G. (1993) Partial cricoid resection with primary tracheal anastomosis for subglottic stenosis in infants and children. Laryngoscope 103, 1273-1283.

[32] Montgomery, W.W. (1973) Posterior and complete laryngeal (glottic) stenosis. Arch. Otolaryngol. $98,170-175$.

[33] Montgomery, W.W. and Montgomery, S.K. (1990) Manual for use of Montgomery laryngeal, tracheal and esophageal prostheses: update 1990. Ann. Otol. Rhinol. Laryngol. 99, 2-9.

[34] Narcy, P., Contencin, P., Fligny, I. and Francois, M. (1990) Surgical treatment for laryngotracheal stenosis in the pediatric patient. Arch. Otolaryngol. Head Neck Surg. 116, 1047-1050.

[35] Ochi, J.W., Evans, J.N.G. and Bailey, C.M. (1992) Pediatric airway reconstruction at Great Ormond Street: a 10-year review. I Laryngotracheoplasty and laryngotracheal reconstruction. Ann. Otol. Rhinol. Laryngol. 101, 465-468.

[36] Ochi, J.W., Evans, J.N.G. and Bailey, C.M. (1992) Pediatric airway reconstruction at Great Ormond Street: a 10-year review. II Revisional airway reconstruction. Ann. Otol. Rhinol. Laryngol. 101, 595-597.

[37] Prescott, C.A.J. and Laing, D. (1993) Medium term fate of cartilage grafts from children after laryngo-tracheplasty. Int. J. Pediatr. Otorhinolaryngol. 27, 163-171.

[38] Rethi, A. (1956) An operation for cicatricial stenosis of the larynx. J. Laryngol. 70, 283-293.

[39] Schuller, D.E. (1980) Long-term stenting for laryngotracheal stenosis. Ann. Otol. Rhinol. Laryngol. $896,515-520$.

[40] Seid, A.B., Pransky, S.M. and Kearns, D.B. (1991) One-stage laryngotracheoplasty. Arch. Otolaryngol. Head Neck Surg. 117, 408-410.

[41] Weerda, H., Zollner, C. and Schlenter, W. (1986) Die Behandlung der Stenosen des laryngo-trachealen Überganges und der zervikalen trachea. HNO 34 (4), 156-163.

[42] Wiatrak, B.J. and Cotton, R.T. (1992) Anastomosis of the cervical trachea in children. Arch. Otolaryngol. Head Neck Surg. 118, 58-62.

[43] Wong, M.L., Finnegan, D.A., Kashima, H.K. and Jafek, B.W. (1978) Vascularized hyoid interposition for subglottic and upper tracheal stenosis. Ann. Otol. 87, 491-497.

[44] Zalzal, G.H. (1988) Use of stents in laryngotracheal reconstruction in children: indications, technical considerations and complications. Laryngoscope 98, 849-854.

[45] Zalzal, G.H. (1992) Stenting for pediatric laryngotracheal stenosis. Ann. Otol. Rhinol. Laryngol. $101,651-655$.

[46] Zalzal, G.H. (1993) Treatment of laryngotracheal stenosis with anterior and posterior grafts: a report of 41 children. Arch. Otolaryngol. Head Neck Surg. 119, 82-86. 